\title{
A UNIVERSIDADE DE ONTE A HOXE: DA ANTIGÜIDADE Á CALIDADE. SITUACIÓN DO SISTEMA UNIVERSITARIO DE GALICIA.
}

DÍEZ DE CASTRO, José Alberto

LÓPEZ PEREIRA, J. Eduardo

de MIGUEL DOMÍNGUEZ, José Carlos

VÁZQUEZ ROZAS, M. a Emilia

\author{
Secretario Xeral de Universidades, \\ Xunta de Galicia \\ Director da ACSUG, Xunta de Galicia \\ Profesor "ad honorem" USC \\ Decana da Facultade de Ciências \\ Económicas e Empresariais da USC
}

Érase que se era unha Universidade que se cría que canto máis antiga era, máis valía e así teimaba en abesourar documentos antigos á procura da máis remota orixe posible. Nese ambicioso desexo chegou a imaxinar que nacera en 1088, ata que alguén lle advirtiu que o documento en que se apoiaba era unha clara falsificación medieval e houbo de se conformar con 1188, no mellor dos casos. Pero outras non lle foron detrás e trataron de se igualaren en antigüidade con ela, e a estas alturas nin elas o saben nin nós temos claro cal é a súa antigüidade nin cal delas é a máis antiga. Nin sequera a nosa querida universidade compostelá líbrase de tal sospeita, pois non son poucos os que non comparten que o seu nacemento ou creación se remonte a 1495, como habitualmente se nos fai crer.

En todo caso, a Universidade como institución cunha organización formal data da Europa medieval, malia que ten antecedentes nas culturas grega, romana e arábiga. Nas súas orixes xorden como unha evolución das escolas medievais coñecidas como studium generale, que tiñan como misión educar aos empregados e monxes en niveis superiores aos que se ensinaba nas escolas monásticas e catedralicias. Nelas aprendíanse as artes liberais: gramática, lóxica, retórica, xeometría, aritmética, astronomía e música. A continuación, os alumnos tiñan a posibilidade de continuar os seus estudos nunha das facultades superiores: leis, teoloxía e medicina.

Este esquema replícase por toda Europa Occidental de forma case homoxénea ata o século XVI no que a contidos se refire, pero con distintas variantes no relativo á administración e xestión da institución, auspiciadas e fundadas por papas, emperadores e reis, que lles permitían gobernarse de forma autónoma, co requisito de non difundir nin o ateísmo nin a herexía. 0 prezo da autonomía, porén, era que as universidades se debían financiar elas mesmas. Desta forma os profesores cobraban honorarios e, para garantir a súa mantenza, tiñan que compracer aos seus estudantes. Estas primeiras universidades non tiñan edificios permanentes e posuían escasas propiedades, estando suxeitas á perda de estudantes e mestros descontentos que se podían desprazar a outra cidade e estabelecer o seu lugar de estudo aló. Esta foi a causa fundacional dalgunhas das máis prestixiosas universidades europeas.

É na metade do século XVI cando a Reforma protestante e a conseguinte Contrarreforma afectan ás universidades xa que se fundan centros que postulan os ideais dun ou outro signo, adicando o seu esforzo formativo á defensa das súas correspondentes doutrinas relixiosas, non prestando demasiada atención ás novas ciencias que comezaran a aparecer ao longo de Europa, o que provocou un período de relativo declive nestas institucións. 
Durante os dous séculos seguintes XVII e XVIII, as universidades comezaron a se diversificaren e a tomar conciencia das súas funcións e do seu papel na sociedade. Consideráronse a elas mesmas como as institucións coa encomenda de impartir educación superior, que foran lexitimadas polas autoridades de cada rexión mediante a facultade de outorgar graos.

Foron renunciando paulatinamente á ortodoxia relixiosa de calquera tipo a favor da preocupación intelectual racional e obxectiva, e así mesmo foron substituíndo o latín como medio de transmisión do coñecemento pola súa respectiva lingua vernácula.

É xa no século XIX cando se adoptan as normas de liberdade académica nas que as conxecturas foron substituídas pola experimentación en laboratorio, a teoloxía, a filosofía e as outras doutrinas tradicionais foron examinadas dun modo máis rigoroso e obxectivo. É daquela cando a investigación se incorpora ao quefacer universitario nun nivel de igualdade coa docencia que fora a causa fundacional da institución. Ata ese momento moitos dos grandes investigadores europeos que todos temos en mente realizaban os seus experimentos e modelaban as súas teorías nun eido alleo ás universidades.

No século XX florecían institucións de educación superior que incorporaban a todas as ciencias dentro dos seus programas de estudo, que competían polos mellores profesores e os alumnos máis capaces, e que levaban a cabo programas de investigación e de difusión da cultura. 0 tamaño das universidades tamén creceu substancialmente e convertéronse en organizacións cada vez máis complexas e heteroxéneas. De pequenas comunidades de profesores e alumnos que levaban unha vida case familiar, pasaron a ser conxuntos de comunidades con intereses diversos, e en ocasións encontrados: a comunidade dos alumnos de grao e os alumnos de posgrao; a comunidade de humanistas, a de científicos e a de científicos sociais; as comunidades das diversas escolas profesionais; a comunidade do persoal de administración e servizos, etc. Ante isto, algún autor propuxo que un nome máis axeitado para a universidade actual sería o de "multiversidade" xa que non se aprecia unha comunidade cunha soa alma e un único principio que a guíe.

A finais deste século XX difundiuse a conciencia de que as institucións deberían non só ser máis eficientes, senón tamén máis responsables coas necesidades tanto dos seus usuarios como da sociedade que contribúe á súa mantenza. Dito doutro xeito, solicítase unha maior repercusión da universidade na sociedade, polo que xorde unha misión baseada nunha actividade de transferencia do coñecemento e da tecnoloxía que debe reverter resultados no desenvolvemento e na competitividade das economías da súa contorna, incorporándose a devandita transferencia ao quefacer das universidades, así como á formación ao longo da vida.

Esta é a universidade que coñecemos hoxe en día: grande, complexa, plural, cunha organización un tanto indefinida e cunha chea de funcións que se foron incorporando ao longo dos séculos: dende a docencia de grao ou equivalente, función primixenia da institución, ata a investigación e formación de posgrao; dende a internacionalización, coa atracción de profesores e alumnos de distintos países, á prestación de servizos á comunidade universitaria, a través de Colexios Maiores, bibliotecas, instalacións deportivas e un amplo etcétera.

Neste devir das institucións de ensino superior utilizouse, ao longo da súa historia, a súa antigüidade como sinónimo de importancia e valía. Pero esta idea de identificar valía con antigüidade derrubouse en 1999, a partir da coñecida como Declaración de Boloña, cando o que comezou a valorarse e a terse en conta non foi a antigüidade, senón a calidade. Desta forma, as universidades máis novas podían competir en valores coas antigas 
universidades medievais europeas. Así foi como se crearon os ránkings actuais, nos que novas universidades americanas, chinesas ou xaponesas copan os primeiros postos.

Europa, o berce da Universidade, cuxa primeira célula de orixe podemos remontar á vella Academia grega (Vivant profesores, vivat Academia, entoamos no noso himno universitario) estaba languidecendo no que a transferencia de coñecemento se refire. Na nosa tradición e na nosa linguaxe levamos a orixe da Universidade. Chamámonos académicos porque así nolo di a nosa ascendencia grega, e chamámonos universitarios só despois do século XIII, cando o termo universitas pasou a adquirir o valor xurídico de "gremio, irmandade, consorcio". Porque unha agrupación ou gremio era o que formaban aqueles estudantes agrupados en torno a uns profesores, a chamada "universitas magistrorum et scholarium", que mediante un acordo entre elas se comprometían uns a ensinar e outros a pagar por ese ensino.

Pero a substitución da antigüidade pola calidade non esclareceu moito ou non esclareceu de todo o problema. Porque, que é a calidade? Deseguida entraron os pedagogos a darnos definicións e complicouse todo. Ducias de definicións pululan polos manuais e repítense de congreso en congreso, de conferencia en conferencia, de coloquio en coloquio, sen que se cheguen a poñer de acordo entre eles, e menos a poñernos de acordo a nós con eles. Pero non é o momento de perdernos por aquí. Nin é esta a senda máis estreita. Para estreito está o que vos vou introducir agora.

E é que se difícil é definir e saber que é a calidade, medila xa se volve de todo imposible. Como medir a calidade? Europa, os 32 países que asumiron a Declaración de Boloña, estableceu a metodoloxía seguinte: unhas axencias de calidade que se van a encargar de medir coordinadamente a calidade de todas e cada unha das universidades europeas cuns criterios comúns e uns estándares de calidade previamente establecidos. É así como se crearon as axencias para a calidade das universidades europeas. Son 51 neste intre que representan a 37 países, dende Inglaterra a Kazajistán, entre as que se atopa a Axencia para a Calidade do Sistema Universitario de Galicia (ACSUG), responsable do control e da garantía da calidade das universidades galegas.

É verdade que a palabra control nos renxe no ouvido e ademais a acción de control nos amola claramente. Pero tamén é verdade que sen control non hai garantía. E que controla a ACSUG? 0 que en Europa deseñamos entre todos. Nin máis nin menos que o que controla a axencia inglesa, a noruega, a alemá ou a rusa. Todos manexamos os Standards and Guidelines for Quality Assurance in the European Higher Education Area (2015), traducidos ao galego como "Criterios e directrices para a garantía de calidade no espazo europeo de educación superior".

Con iso, todos, axencias e universidades, e por suposto os gobernos e as administracións, perseguimos un mesmo obxectivo: a mellora continua da calidade das nosas universidades, na idea de que sabemos que a calidade é unha meta que sempre se persegue sen que se acade nunca, porque sempre é posible un nivel de calidade maior.

Con esta misión naceron as axencias en toda Europa (e hoxe tamén xa en Asia Central) logo do acordo de Boloña.

As universidades tiveron que cambiar o modelo formativo, adaptar os plans de estudo e se comprometeron cun novo modelo de ensino, cambiando o seu obxectivo de ensinar polo de aprender: o que primeiro interesa é que o alumno aprenda e logo comprobar que realmente adquira as competencias que se fixaron previamente. $E$ isto introduce un novo factor, un novo stakeholder: a sociedade na que está inmersa a universidade, porque ela 
manifiesta as súas necesidades e solicita da universidade que lle aporte eses titulados que van necesitar.

Daí que á ACSUG se lle encomendara primeiro o control dos títulos a través do proceso de Verificación, Seguimento e Acreditación e a certificación dos Sistemas Internos de Garantía da calidade (SIGC), e despois os resultados dos titulados no que a competencias, empregabilidade e satisfacción se refire.

Pero, cal é neste momentos a situación do Sistema Universitario de Galicia (SUG) transcorridos 28 anos dende a creación das Universidades de A Coruña e Vigo, que coa de Santiago de Compostela completan o mapa do sistema?

A foto fixa actual é a seguinte:

Racionalización do tamaño do SUG: as tres universidades galegas e os sete campus ofertan hoxe 118 graos e 175 másteres.

Plan de financiamento ata 2020: garantiza a sustentabilidade do sistema e impulsa a consecución de resultados en $\mathrm{I}+\mathrm{D}+\mathrm{i}$.

Estratexia de especialización: ademais do Campus Vida (USC) e o Campus do Mar (UVI), impulsouse a especialización nos campus non centrais a través do Campus Auga (Ourense), do Campus Terra (Lugo) e do Campus Industrial (Ferrol), seguindo por este camiño co Campus Crea (Pontevedra), e os Campus Innova e Campus de Sustentabilidade (A Coruña), o Campus Vigo Tecnolóxico e o Campus da Cidadanía (Santiago).

Investigación vencellada á excelencia: ademais de garantir as convocatorias para seguir formando recursos humanos, sentáronse as bases do modelo galego de investigación, liderado por centros singulares e agrupacións estratéxicas.

Mellora na empregabilidade dos titulados: o derradeiro estudo de inserción laboral do SUG amosa que o 70,59\% dos titulados durante o curso 2012/2013 traballaba no momento da realización da enquisa, o que supón o mellor dato, destas características, dende o curso 2005/2006.

Ademais desta foto actual do SUG, debemos ter en conta un plan de dez medidas froito dun pacto entre a Secretaría Xeral de Universidades da Xunta de Galicia e as tres universidades galegas, para reforzar a calidade do sistema, a instituír nos vindeiros anos, e que se detallan a continuación.

1. Graos interuniversitarios

Liña de acción fundamental. Impulsa a colaboración e a unión de forzas entre as institucións académicas, mellorando a eficiencia na xestión e na docencia.

2. Graos en inglés

Consiste na creación dun grupo diferenciado en inglés dentro da oferta dun título de grao.

Cuns requisitos mínimos para a súa institución: 0 80\% dos créditos débense impartir en lingua inglesa, e será necesario un mínimo de 20 alumnos matriculados no primeiro curso neste grupo; sendo compromiso das universidades mantelo durante catro cursos consecutivos.

3. Mellora nos ránkings internacionais 
O obxectivo é acadar unha mellora na posición das universidades galegas nos principais ránkings a nivel internacional.

Para iso seleccionáronse tres: o Academic Ranking of World Universities (ARWU), máis coñecido como ránking de Shanghai; o Times Higher Education; e o QS World University Rankings.

As universidades do SUG deberán presentar unha proposta de mellora, incluíndo os contidos e a descrición das accións, así como o impacto previsto nos seus resultados nun prazo temporal de tres anos.

A elección das devanditas accións a emprender son totalmente libres, sempre con referencia aos criterios de valoración en docencia, I+D, reputación, internacionalización e outros.

4. Mapa de empregabilidade

A Secretaría Xeral de Universidades da Xunta de Galicia elaborará un mapa de empregabilidade con información útil sobre a oferta académica para o futuro alumnado universitario. Para iso, utilizaranse a enquisa sobre titulados universitarios que realiza anualmente a ACSUG; indicadores de emprego procedentes do sistema español centralizado de información universitaria; e seguimento das cotizacións á Seguridade Social dos titulados.

Os datos incorporaranse a nivel de título e de universidade.

5. Premios á excelencia académica Concepción Arenal.

Serán axudas para premiar o rendemento académico do alumnado, e teñen como finalidade potenciar a excelencia no estudo curso a curso e non só ao rematar a carreira.

6. Complemento de transferencia do coñecemento

Crearase este novo complemento retributivo para recoñecer ao profesorado que realice actividades de transferencia de coñecemento á sociedade. 0 obxectivo desta medida é o de incentivar ao persoal docente e investigador no cumprimento da terceira misión da universidade galega, así o coñecemento e as investigacións do PDI pódense revertir na sociedade para impulsar o seu progreso socioeconómico.

7. Másteres oficiais de excelencia

Recibirán unha mención específica de excelencia aqueles másteres oficiais que reúnan unha serie de características sobresaíntes. Entre elas: unha importante internacionalización do alumnado e profesorado, gran demanda laboral, alta empregabilidade, profesorado especialista de primeiro nivel; seguimento do alumnado, captación de recursos externos, e mecanismos de revisión continua do plan de estudos.

8. Captación de alumnado universitario iberoamericano

0 descenso de alumnado universitario dende o comezo do presente século, que pasou de 98.691 no curso 1999/2000 a 59.353 no 2013/2014, supón un descenso de aproximadamente un $40 \%$ debido a distintas causas: pirámide de poboación, paso dos 5 anos para as licenciaturas aos 4 dos graos, competencia tanto da Formación Profesional superior como do ensino a distancia. 
Para tratar de paliar no futuro esta perda lenta pero constante de estudantes, a Secretaría Xeral de Universidades en colaboración con outros departamentos da Xunta de Galicia e as tres universidades do SUG, realizarán unha serie de misións de atracción de alumnado en Iberoamérica para os graos e másteres do SUG. Especialmente cóntase coa colaboración da Secretaría Xeral de Emigración para difundir estas accións á colectividade galega no exterior.

9. Xestión de unidades de excelencia investigadora no SUG

Trátase dun programa formativo en xestión estratéxica de centros de investigación de excelencia, en colaboración coa Fundación EmpresaUniversidade Galega (FEUGA). Consta de dúas modalidades: Xestión Estratéxica de Centros e Unidades de Investigación e Xestión Operativa en Centros e Unidades de Investigación.

É unha iniciativa de formación de alto nivel inédita en España, dirixida e deseñada especificamente para a contorna investigadora.

Con esta acción preténdese impulsar a competitividade, a excelencia e a mellora continua dos centros universitarios de investigación galegos. Tratando de mellorar a súa eficiencia e conseguir acadar fitos de maior impacto científico e tecnolóxico.

10. Novos perfís profesionais

Esta medida pasa por definir os perfís profesionais do futuro para a economía galega na vindeira década, anticipándose o sistema educativo a estas demandas e co obxecto de que o devandito sistema aspire a ser efectivo en termos de empregabilidade e retención de talento. Ninguén pode predicir o futuro, pero o estudo das principais tendencias permitirá prepararse para intentar anticiparse ao mesmo. 